\title{
ACCELERATED CANINE RETRACTION BY CORTICOTOMY ASSISTED OR PERIODONTAL DISTRACTION
}

\author{
Atia Abdelwareth A.Yousif *, Neveen F. Abo-Taha** and Emad F. Essa***
}

\begin{abstract}
Objectives: Canine retraction was accelerated by periodontal distraction or several surgical techniques depending on the concept that the greater surgical injury to alveolar bone, the greater biological response in the form of localized inflammatory reaction and bone remodeling, hence tooth movement acceleration. The present study aimed to compare between certain surgical techniques and periodontal distraction combined with interseptal bone reduction to accelerate canine distalization.

Patients and Methods: A randomized split mouth clinical multi-operator study was performed on 30 orthodontic patients aged 15 years and above whose treatment procedures were planned for first premolar extractions and subsequent retraction of canines. Canines were distalized by surgery or distraction on one side and by conventional mechanics on the other side (the control side). Subjects were randomized equally into three canine retraction groups: Group I (multipleosteoperforation MOPs); Group II (MOPs+corticotomy) and Group III (periodontal distraction). Canine retraction was carried out by power chain applying $150 \mathrm{~g}$ of force per side. Total time for complete canine retraction was determined and change in canine angulation was assessed using panoramic radiographs.
\end{abstract}

Results: Regarding the time needed for complete canine retraction for all groups, the experimental side(surgical or distraction) showed a statistically significant lower mean value as compared with the non-surgical side. In other words, less than three months in Group I, about two months in Group II and less than one month in Group III, while more than four months in the conventional retraction side was taken for complete canine retraction. the mean canine angulation changes by degree was (11-15.2-23.2-8.1) degree for group I, II III and conventional group respectively.

Conclusion: Canine retraction movement was accelerated effectively by MOPs, corticotomy and periodontal distraction techniques; the fastest of them was the periodontal distraction mechanics. However, it showed more distal tipping and more buccal inclination of the canine than MOPs, corticotomy or conventional canine retraction.

\footnotetext{
* Associate professor of orthodontic -Faculty of Dentistry-TANTA University.

** Lecturer of orthodontic- Faculty of Dentistry-TANTA University

*** Associate professor of oral and maxillofacial surgery- Faculty of Dentistry-TANTA University.
} 


\section{INTRODUCTION}

The duration of orthodontic treatment is very important for patients to know before starting orthodontic treatment. Therefore, any treatment modalities that decrease treatment duration without affecting the results is a main challenge in orthodontic researches ${ }^{(1,2)}$. A number of innovations orthodontic techniques that aimed to shorten orthodontic treatment duration have been described recently ${ }^{(3)}$.

These modalities can be divided into three groups.[1] drugs (prostaglandins ${ }^{(4-6)}$, interleukins ${ }^{(7)}$, leukotrienes ${ }^{(8)}$, cyclic adenosine monophosphate ${ }^{(9)}$, and vitamin D) ${ }^{(10-11)}$. [2] Mechanical or physical stimulation (direct electrical current ${ }^{(12)}$, pulsed electromagnetic field ${ }^{(13)}$, and low-energy laser $)^{(14)}$. [3] Oral surgical procedures that accelerate orthodontic treatment due to disruption of alveolar bone continuity, ${ }^{(15)}$ Or induction of localized inflammatory reaction, which in turn activates osteoclastic activity ${ }^{(16)}$. Also, surgery in the alveolar bone resulted in its injury with subsequent decrease in its bone density thus decreasing its resistance to orthodontic tooth movement ${ }^{(17)}$. A combination of conventional orthodontic and a surgical technique have been done to improve and accelerate the treatment ${ }^{(18)}$. Among these surgical procedures, micro-osteoperforations (MOPs) which is a safe and Less invasive multiple trans-mucosal perforations within alveolar bone which done in the region of desired tooth movement ${ }^{(19-20)}$.

A cute inflammation that induced by MOPs leads to secretions of inflammatory markers as chemokine and cytokine which help in differentiation multinucleated giant cells thus the rate of orthodontic tooth movement can be accelerated ${ }^{(21-22)}$. A corticotomy is another surgical procedure used to accelerate the rate of tooth movement by which the teeth forms a separate block with its own surrounding bone connected with the surrounding structures via medullary bone after cutting the buccal and lingual cortical plates with surgical bur after flab elevation. (18, 23) Actually, orthodontic tooth movement involving corticotomy can be considered as a process of moving blocks of bone rather than moving only the teeth themselves ${ }^{(24)}$. It was reported that corticotomy can accelerate the rate of tooth movement either due to: a alterations within the periodontal ligament, increase in bone turnover, demineralization process in the cancellous bone surrounding the socket, earlier bone resorption due to earlier removal of hyaline and decreased resistance of the dense cortical bone. ${ }^{(25-27)}$

However, the disadvantage of the previous techniques is the need for invasive flap surgery and heavy orthodontic force which increases the risk of periodontal problems and pulpal death so, many trails switched to a less invasive surgical approaches for acceleration of tooth movement. ${ }^{(28)}$ One such mechanical manipulation is distraction of the periodontal ligament which was first applied by Liou and Huang in $\mathbf{1 9 9 8}^{(29)}$ to perform rapid canine retraction through distraction and named dental distraction which is similar to rapid palatal expansion of the mid-palatal suture after undermining and reduction of inter-septal bone thickness and depth distal to the canine ${ }^{(28)}$. Rapid canine distraction leads to faster retraction of incisors in both maxillary and mandibular arches that incisors are retracted immediately into the immature bone created after canine distraction, leading to significant reduction in treatment time (6 to 9 months), without damaging the periodontal ligament, nor affecting tooth vitality ${ }^{(29-30)}$. In the present study canine distraction technique was compared with other surgical modalities used to accelerate maxillary canine retraction to asses' superiority of one technique over another.

\section{AIM OF THE WORK}

The present study was carried out to evaluate the effects of periodontal ligament distraction, 
corticotomy and micro-osteo-perforations (MOPs) on the rate of canine retraction relative to conventional orthodontic retraction technique.

\section{PATIENTS AND METHODS}

\section{Study Design}

It is a randomized split mouth clinical, multioperator study.

\section{Sample Size and Setting}

30 orthodontic patients: from out-patients, attending Orthodontic Department, Faculty of Dentistry, TANTA University. For each patient one side is used for intervention and the opposite side is used as control. The study was performed after receiving the approval of the ethical committee of Faculty of Dentistry, Tanta University and written acceptance consent from each patient participating in the study.

\section{Selection Criteria}

1) patient age: $15-18$ years 2) extraction of all four first premolar teeth as a part of the orthodontic treatment plan ; 3) no systemic disease that may affects the bone; 4) no periodontal disease; 5) good oral hygiene; 6) very good patient compliance; 7) absence of any previous orthodontic treatment.

Continued inclusion of patients in the present

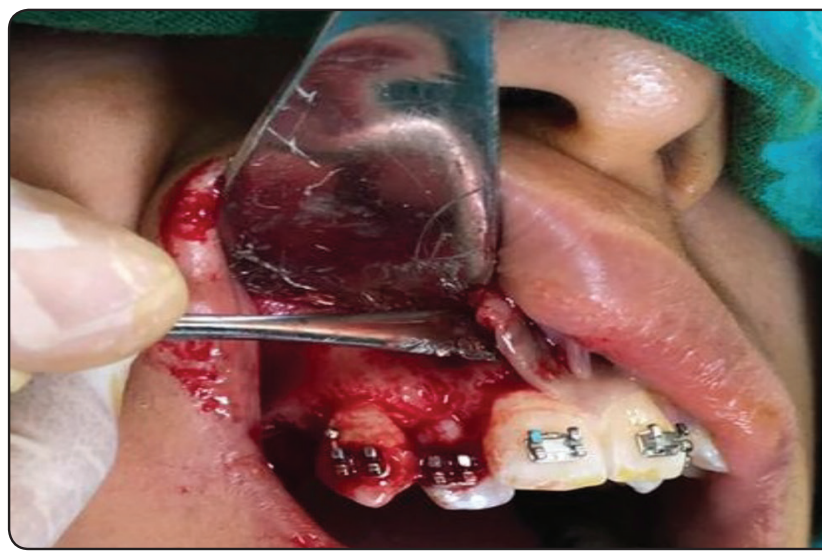

study was carried out to overcome attrition bias (patient drop out) due to poor oral hygiene or bad patient compliances, if patients taking any medications that may affect bone formation and patients with broken appliance or brackets. Till 10 patients in each group reached full canine retraction and attending the orthodontic clinic at a regular short recall visits (every week). The patients received hygiene instructions and every patient received a straight wire Roth fixed appliance (Ormco. USA. $0.022 \times 0.028$ inch slot). Leveling and alignment was performed by using sequential aligning arch wires until reaching a wire gauge of rectangular $0.016 \times$ $0.022 \mathrm{st}$ st arch wire. The patients were divided into three equal groups of 10 patients each. GROUP(I): multiple osteo-perforation (MOPs) group: After extraction of the first premolars as dedicated in the treatment plane, Local anesthesia infiltration was injected in buccal vestibule from lateral incisor to second premolar at side of surgery and palatally. When the area got anesthetized (examined by probe), a muco-periosteal flap was elevated and the cortical bone was exposed on the buccal side of the canine. Three holes $2 \mathrm{~mm}$ wide, $2 \mathrm{~mm}$ depth and $2 \mathrm{~mm}$ apart from each other's along the mesial and distal aspect of the canine root in the inter-dental region were done using round surgical bur for drilling holes with equal widths $(2 \mathrm{~mm}$ ) under normal saline solution irrigation then the flap secured in place by surgical stitching Fig. 1(A \& B) and Fig. 2 (A \& B) 5 days

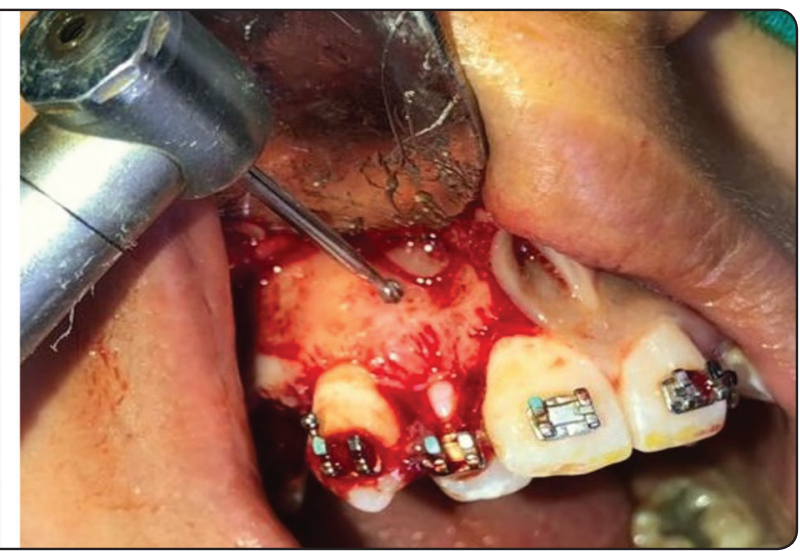

Fig. 1( A \& B) 


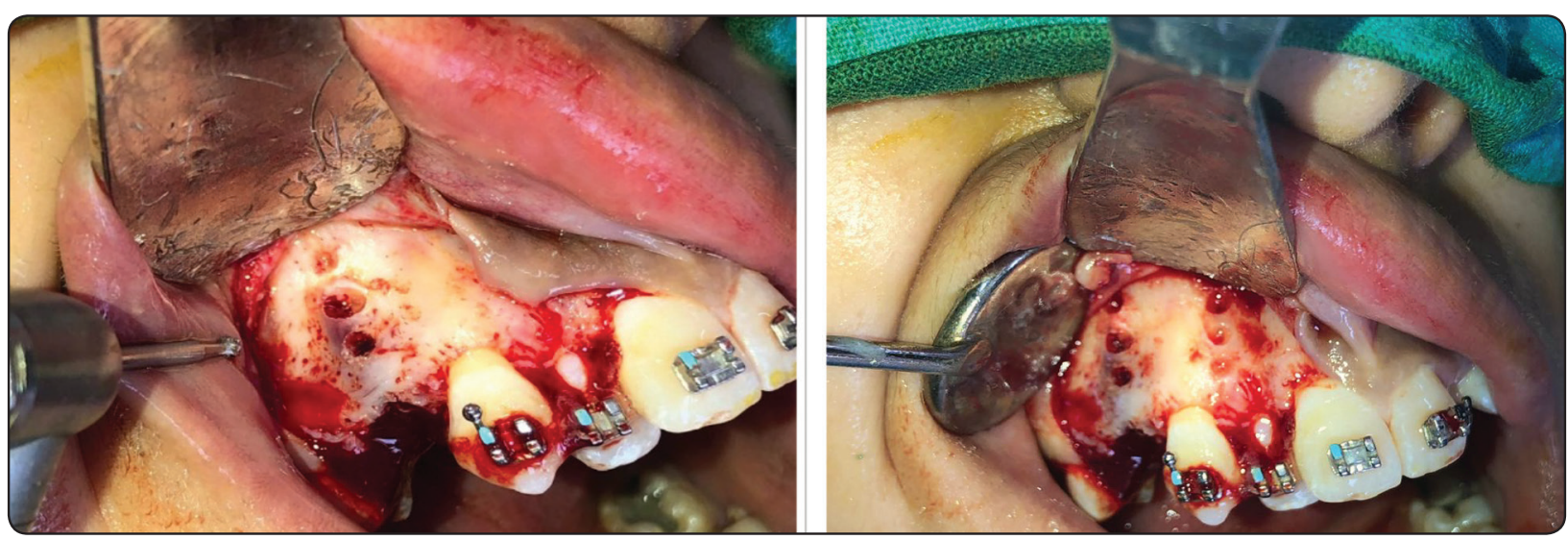

Fig. 2 ( A \& B)

medications in the form of antibiotic (Amoxicillin capsules, $500 \mathrm{mg} 3$ times daily) were prescribed for patients with analgesic (Paracetamol tablet 2 times daily).

\section{GROUP (II): MOPs + corticotomy group:} Similarly as in group I, a muco-periosteal flap was elevated after extraction of the first premolars as planed in the treatment procedure. However, three holes $2 \mathrm{~mm}$ wide, $2 \mathrm{~mm}$ depth and $2 \mathrm{~mm}$ apart from each other's alongside the mesial aspect using round surgical bur and a corticotomy cut along the distal aspect of the canine root in the inter-dental region were done then the flap secured in place by surgical stitching (fig.3).

\section{GROUP (III): Periodontal distraction group:}

After extraction of the first premolar, a long round surgical bur is used in low speed hand-piece with adequate cooling water jet is used to undermine the distal inter-septal bone of the canine via the extraction socket, angulated and passing along buccal, apical and palatal junction of the interseptal bone with the maxillary bone till the interseptal bone became completely undermined (fig.4). A custom made distractor was fabricated using two point palatal expander widely opened and soldered to canine band and molar band which in turn soldered to a trans-palatal arch then cemented intraorally (fig.5,6,7).

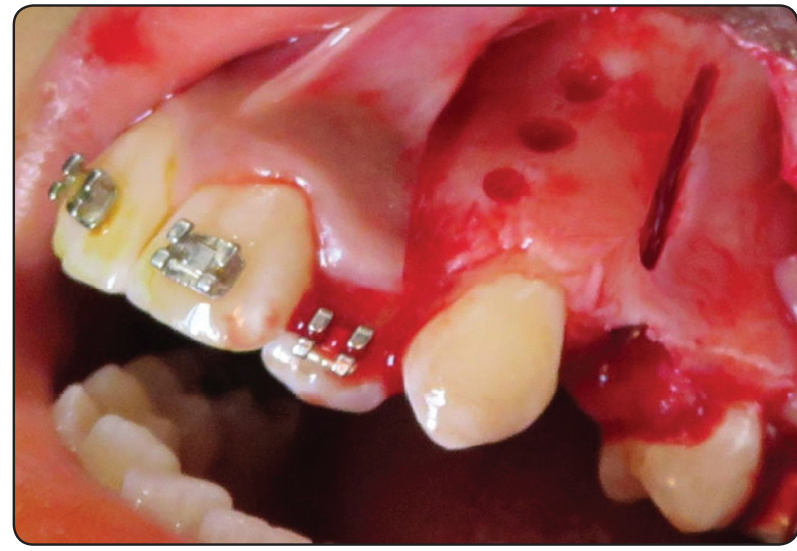

Fig. (3)

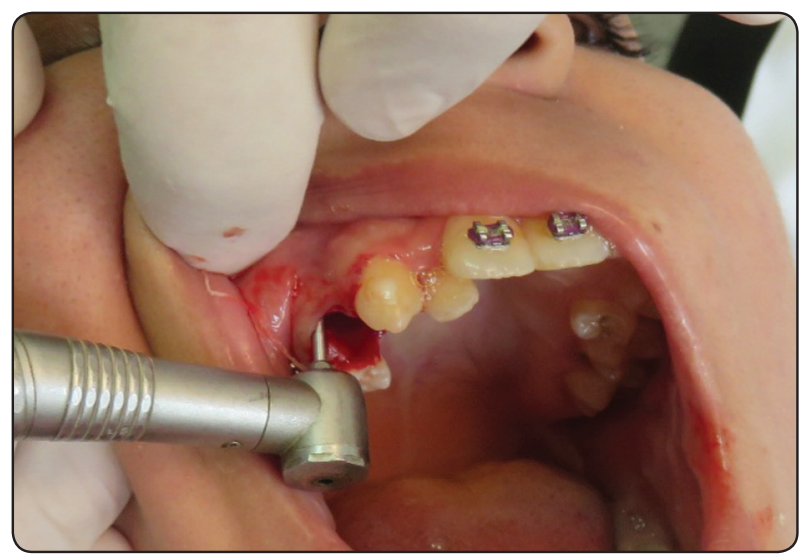

Fig. (4) 


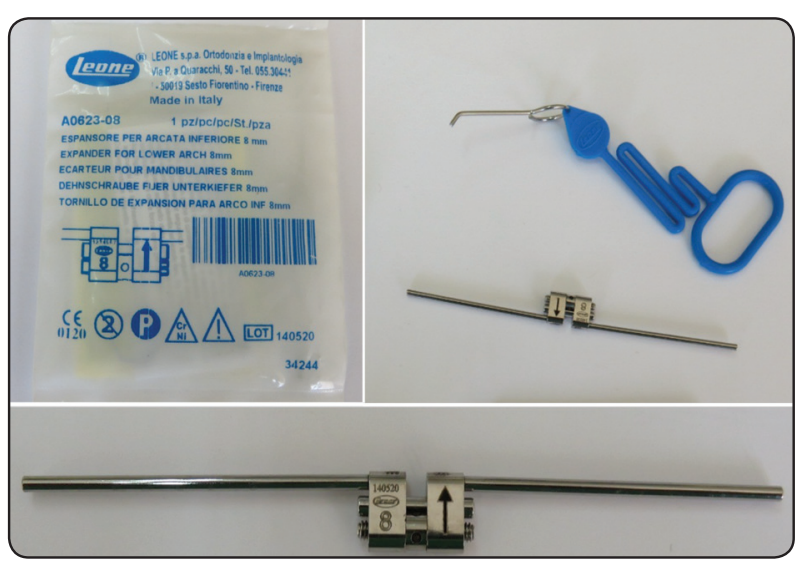

Fig. (5) Expansion screw and its key

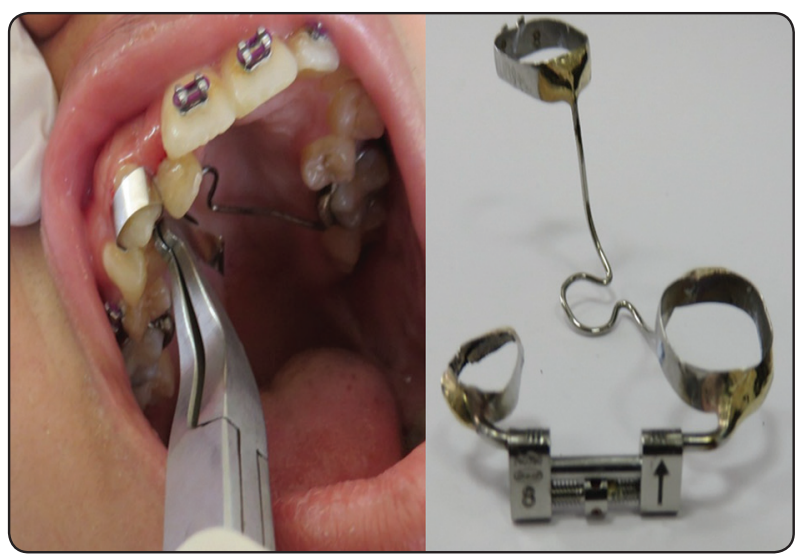

Fig. (6) Complete distractor with arms soldered to canine and molar bands

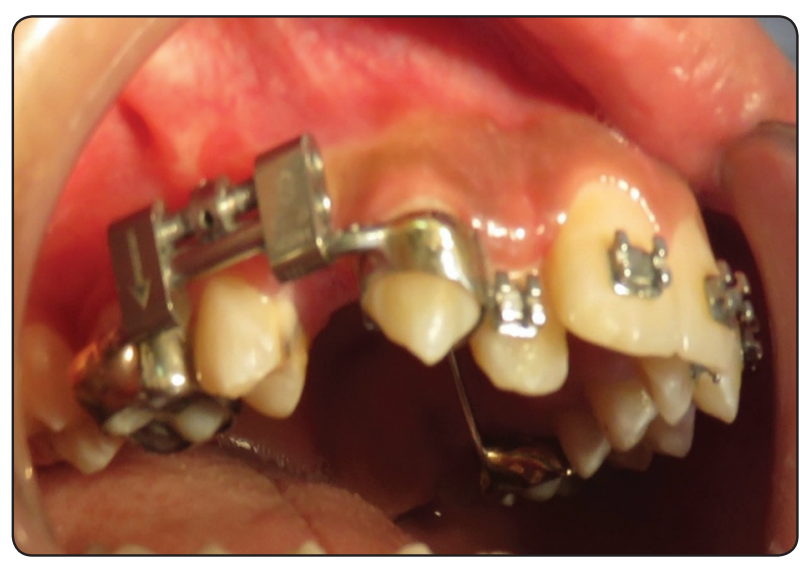

Fig. (7) Cemented distractor intra-orally

\section{Control group: conventional canine retraction}

In each of the previous three groups, one side was considered as an experimental side, and the opposite side is used as control. So in the control side, the canine was retracted conventionally using elastomeric chain that apply force equal to 150 gram and replaced every three days to avoid force dissemination The force level was measured using tension gauge and kept as much as possible about 150 grams (fig. 8).

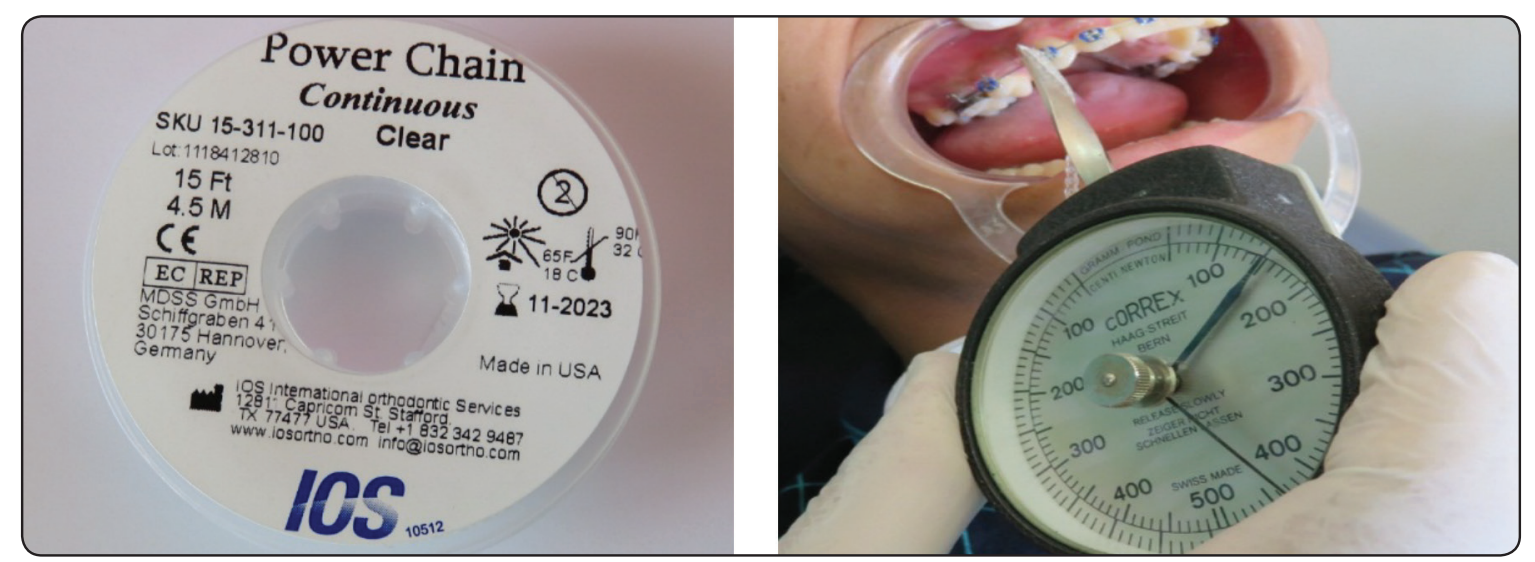

Fig. (8) Power chain and tension gauge 


\section{Activation protocol}

For all groups, a trans-palatal arch was incorporated in the appliance to maximize the anchorage. In group (I), group (II) and control group, canine retraction was started soon after the operation using elastomeric chain after calibrating the retraction force using tension gauge that (150 g) of force was applied. The elastomeric chain was replaced every three days and adjusting the retraction force to avoid dissemination of the force exerted by elastic chain. While in group III, distractor activation initiated immediately after surgery. Activations were performed by turning the screw $0.25 \mathrm{~mm}$ every 12 hour (two turns per day).

\section{Determination of the distance of canine retraction}

The distance between the distal surface of the canine and the mesial surface of the second premolar was recorded directly in patient's mouth every week using a caliper with $0.01 \mathrm{~mm}$ scale (Dentaurum, Germany) (fig. 9), and the total time required for complete retraction of the canine was calculated.

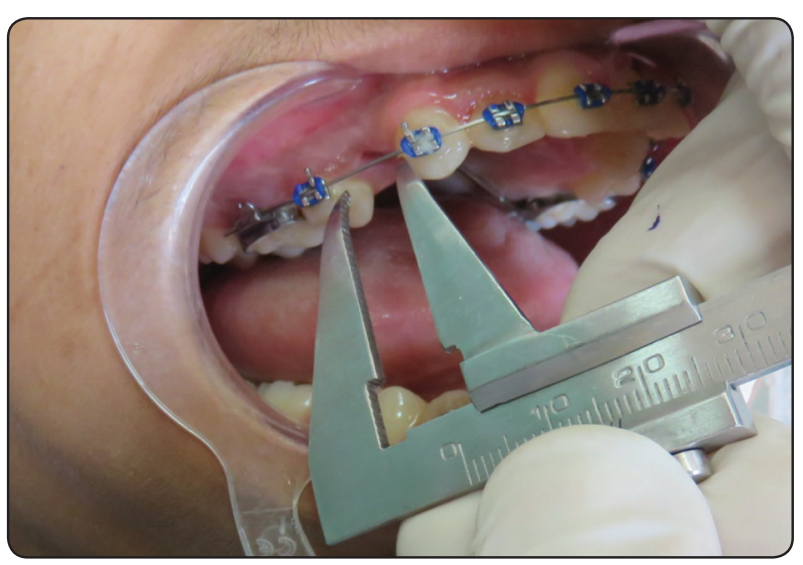

Fig. (9) Sliding caliper

\section{Panoramic Radiographic Analysis of canine an- gulation before and after retraction}

Canine angulation changes were assessed by analyzing the panoramic radiographs taken before and after the retraction completion. A line representing the long axis of the canine passing from the canine cusp tip through the root apex to intersect with a line connecting the right and left orbitale and the angle of intersection was measured before and after canine retraction in all groups $^{(31)}$ (fig.10,11 A \& B).

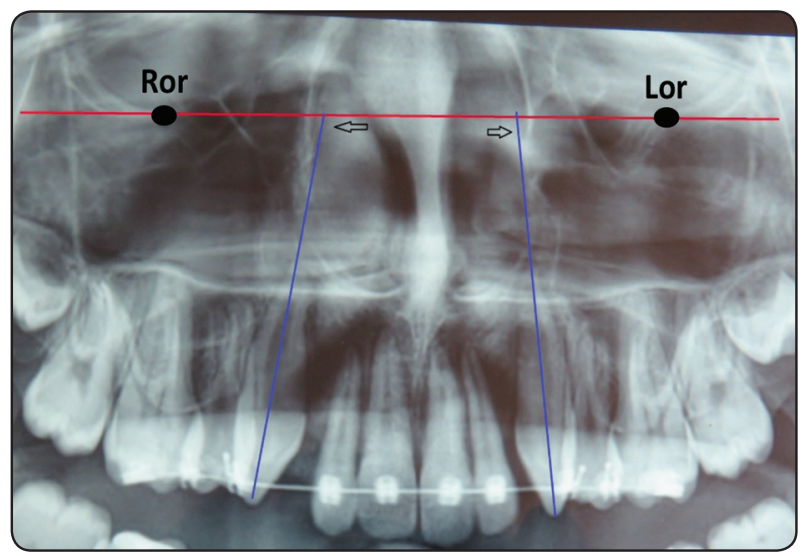

Fig. (10) Distal tipping angle of the canine relative to line connecting the right and left orbitale points

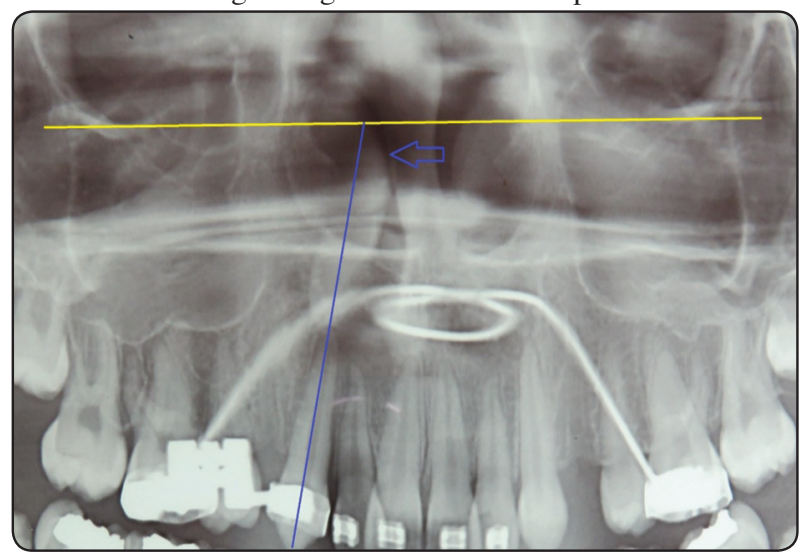

Fig. (11A)

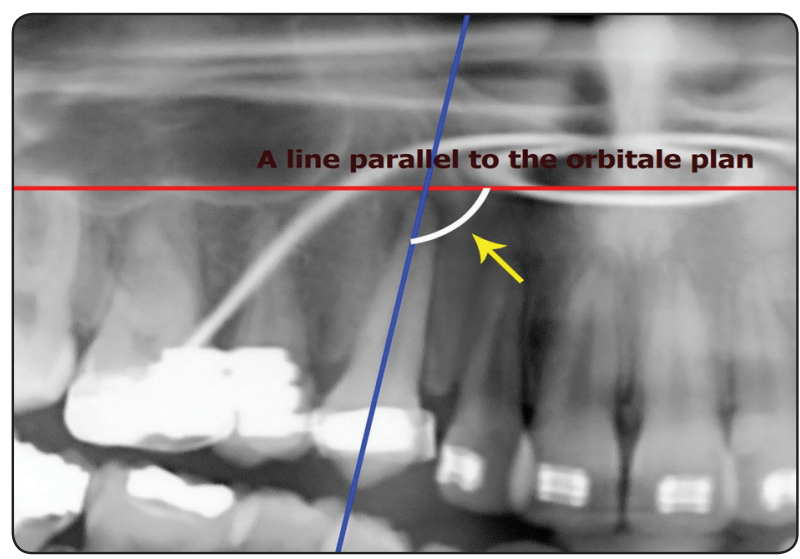

Fig. (11B) 


\section{Statistical analysis}

Descriptive data were presented as mean $\pm \mathrm{SD}$ and range values. The intervention groups and the control group were compared by ANOVA test (confidence level $95 \%$ and $\mathrm{P} \leq 0.05$ ).

\section{RESULTS}

\section{Clinical complications and side effects}

In periodontal distraction group, patients only reported pain and discomfort due to the bulkiness of the distraction appliance that dissipated within minutes. Moreover, slight pressure on teeth was felt by the patients on activation of the screw. Greater distal tipping and buccal inclination of the canine in periodontal distraction group because of the location of the distractor too far buccal relative to the center of resistance.

\section{Time determination for complete canine retraction}

Regarding the time needed for complete canine retraction, the surgical side showed a higher mean value as compared with the non-surgical side in all groups which was statistically highly significant. The canine retraction was accelerated by $22 \%$ for group (I), 38.5\% in group (II) and this value nearly duplicated in group (III) when a rigid distractor was used after undermining the inter-septal bone greater than the non-surgical side as shown in table (1) and figure (12).

\section{Assessment of canine angulation}

The results of the panoramic radiographic analysis indicated that in periodontal distraction group, despite the use of rigid type distractor, canines experienced an average distal inclination of 20 to 25 degrees during distalization which was statistically highly significant when compared with other groups. A non-statistical angular difference was found when MOPs was compared with conventional retraction, while MOPs and corticotomy (group II) showed a significant difference when compared with conventional retraction as shown in table (2) and figure (13).

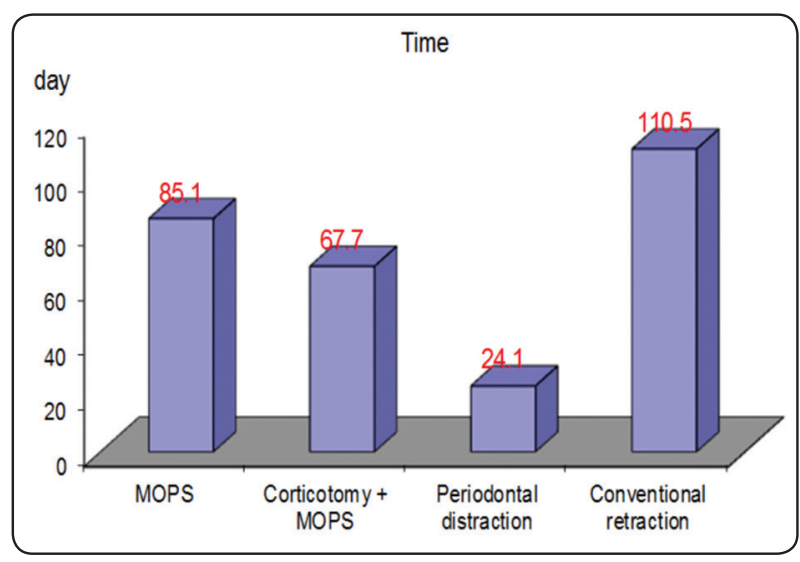

Fig. (12): mean of canine movement time in all groups

TABLE (1) Descriptive statistics of canine movement time in all groups

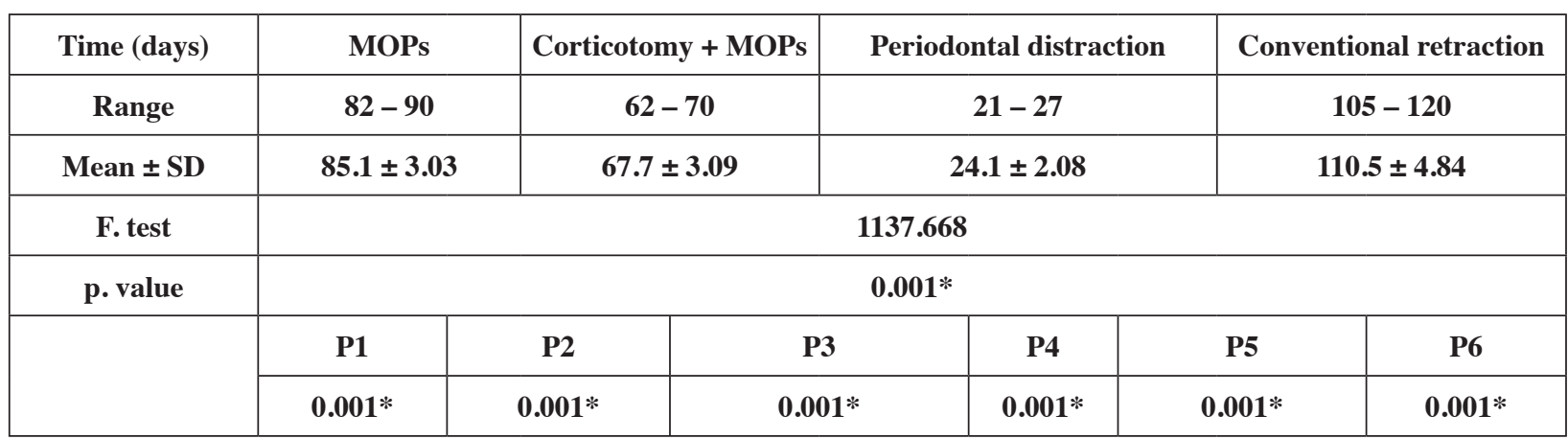

*Statistically significant at $P \leq 0.05$

P1: MOPs \& Corticotomy + MOPs. P2: MOPs \& Periodontal distraction. P3: MOPs \& Conventional retraction. P4: Corticotomy + MOPs \& Periodontal distraction. P5: Corticotomy + MOPs \& Conventional retraction. P6:

Periodontal distraction \& Conventional retraction. 
TABLE (2) Angular canine changes in all groups

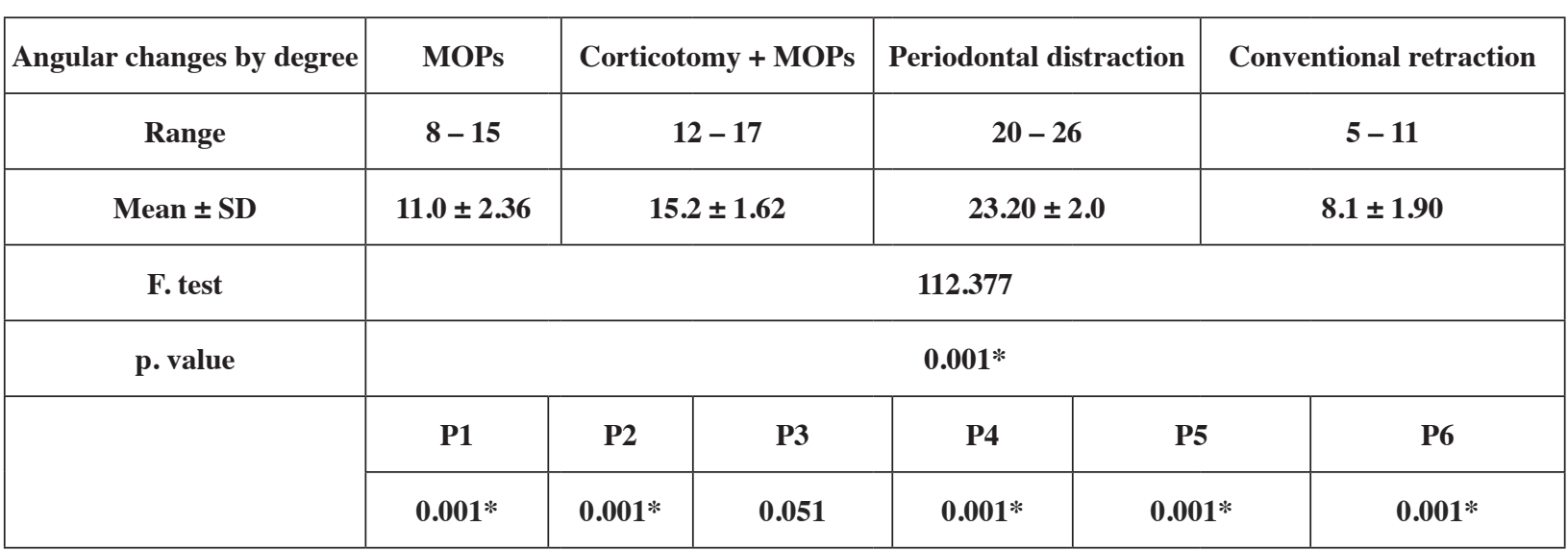

*Statistically significant at $P \leq \mathbf{0 . 0 5}$

P3: MOPs \& Conventional retraction.
P1: MOPs \& Corticotomy + MOPs. P2: MOPs \& Periodontal distraction.

P4: Corticotomy + MOPs \& Periodontal distraction.

P5: Corticotomy + MOPs \& Conventional retraction. P6: Periodontal distraction \& Conventional retraction.

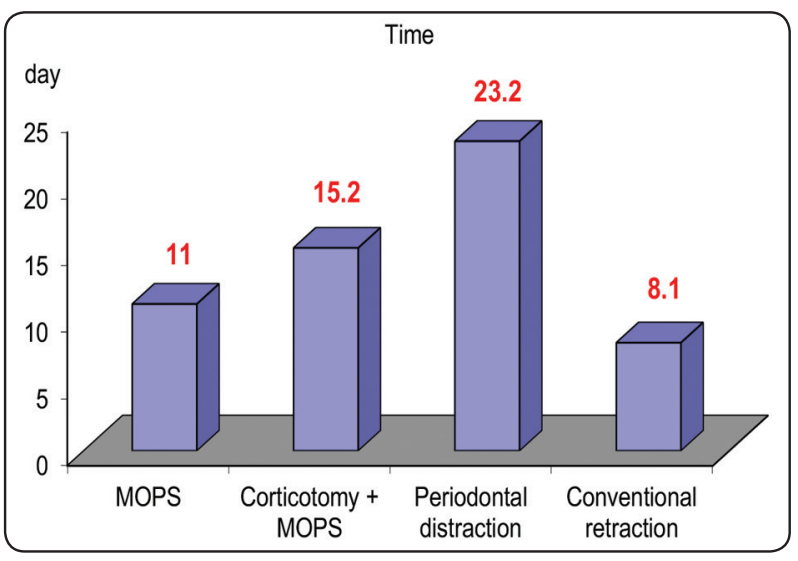

Fig. (13): mean of the canine distal angular tipping in all groups

\section{DISCUSSION}

Conventional orthodontic treatment especially that involves extraction therapy is long treatment time; it may last for about 31 months ${ }^{(32)}$. Therefore, many patients may avoid orthodontic treatment ${ }^{(18)}$. Long orthodontic treatment time may resulted in root resorption, gingivitis, and caries ${ }^{(33)}$. So, recently decreasing treatment time by accelerating the rate of tooth movement considered an aim in orthodontic practice. ${ }^{(34)}$. Several techniques of rapid canine retraction can be used as alveolar surgery and distraction osteogenesis ${ }^{(17)}$ which accelerates the bone resorption, and osteoclast activity ${ }^{(35)}$. Also, because surgical injury to alveolar bone such as corticotomy and MOPs can induce local inflammatory reaction, chemokine and cytokine levels are elevated, hence osteoclast stimulation and tooth movement acceleration ${ }^{(1,36)}$. However, these techniques involve invasive flap surgery; so, a novel simplified flapless approach was performed to accelerate the rate of canine movement by periodontal ligament distraction which was reported as technique not resulted in damage to the periodontal ligament, nor affected pulp vitality ${ }^{(37)}$. The aim of the present study was to evaluate the effects of periodontal ligament distraction combined with interseptal bone reduction, corticotomy and microosteo-perforations (MOPs) on the rate of canine retraction relative to conventional orthodontic retraction technique. As tooth movement strongly affected by bone density and osteoclastic activity so age of the patient was considered an important factor. ${ }^{(38-39)}$ so in the present study the age of all patients ranging from 15 to 18 year at the start of treatment and the average ages in all groups were similar. 
The eligibility criteria was set to exclude patients with poor oral hygiene, periodontal disease, alveolar bone defects, systemic diseases that may affects the bone, and administration of any medications that may modulate the bone response ${ }^{(40-41)}$.

By making a split-mouth study the reliability of the results were assured by taking the result of the intervention and control from the same patient

\section{Duration of canine retraction}

In the present study, the mean canine retraction time was $85.1 \pm 3.03,67.7 \pm 3.09$ and $24.1 \pm 2.08$ days in the surgical side that represented by group I (MOPs), group II (corticotomy+MOPs) and group III (periodontal distraction) respectively, these mean values were significantly lower than the mean value (110.5 \pm 4.84 days) of canine retraction in the nonsurgical side (conventional retraction).

Regarding the time needed for complete canine retraction procedure, it was found that more than four months were taken to completely retract the canine by conventional mechanics, less than three months for MOPs group, about two months in corticotomy+MOPs group while in periodontal distraction group, only less than one month was taken for complete canine retraction. There were high significant differences among all groups. In the periodontal distraction group, the results were in accordance with Kumar et al. ${ }^{(42)}$ who performed periodontal distraction and completed canine retraction in three and half weeks. A similar findings were obtained from the study of Liou and Huang ${ }^{(29)}$ and Sayin et al..$^{(4)}$ as they stated that complete rapid canine retraction can be done in three weeks. Also the results of the present study came in accordance with Kharkhar et al. ${ }^{(44)}$ and Kateel et $\mathrm{al}^{(37)}$ in which the mean time of complete canine retraction was $19.5 \pm 1.7$ and $15.38 \pm 1.51$ days respectively. Some possible reasons for the variation in canine retraction duration can be attributed to the resistance of bone fragments that may hinder the desired tooth movement, also different mechanics and different distractor design and time of activation can be considered a factor

\section{Changes in canine angulation}

In periodontal distraction group, canines showed the highest significant distal inclination of 20 to 26 degrees with a mean change of $23.20 \pm 2.0$ during distalization among all groups even when compared with the conventional retraction mechanics. This could be attributed to the location of the distractor too far buccal relative to the center of resistance.

Regarding the angular distal tipping of the canine numerous previous studies came in accordance with the present study as Liou and Huang ${ }^{(29)}$ who found that $17^{\circ}$ of distal tipping, while Sayin et al. ${ }^{(43)}$, Kumar et al..$^{(42)}$ and Kateel et $\mathrm{al}^{(37)}$ reported distal tipping of canines by $11.4^{\circ}, 15.2^{\circ}$ and $14.9^{\circ}$ respectively. This variation in angular change may be due to the anatomical factor close to the apex of canine, variation in bone density, position differences of the arm of the distractor on canine and difference in measurement reference points.

\section{CONCLUSIONS}

- Rapid canine retraction by accelerated techniques especially periodontal distraction in conjunction with the use of rigid type distractor provides significant reduction in orthodontic treatment time than retraction with conventional technique.

- Periodontal ligament distraction resulted in more distal tipping and more buccal inclination of the canine than MOPs, corticotomy or conventional canine retraction.

- Further researches are required with distractors in conjunction with biomechanics that counteract distal tipping of the canine is needed. 


\section{REFERENCES}

1. Mani Alikhani, Markos Raptis, Billie Zoldan, Chinapa Sangsuwon,Yoo B. Lee, Bandar Alyami, Corey Corpodian, Luz M. Barrera, Sarah Alansari, Edmund Khoo, and Cristina Teixeirak New York, NY. Effect of microosteoperforations on the rate of tooth movement. Am J Orthod Dentofacial Orthop 2013;144:639-48.

2. Yamile Zamora Escobar, Francisco José Murillo Samper. Micro-osteoperforations for accelerating tooth movement during canine distalization,split-mouth study. Case report. Micro-oseoperforaciones para acelerar el movimiento ortodóncico en distalización canina, estudio en boca dividida. Reporte de un caso. Revista Mexicana de Ortodoncia. Vol. 5, No. 4 October-December 2017. 201209.

3. Nimeri G,Kau CH,Abou-Kheir NS, Corona R.Acceleration of tooth movement during orthodontic treatment-a frontier in orthodontics. Prog Orthod. 2013;14:42.

4. Yamasaki K, Shibata Y, Fukuhara T. The effect of prostaglandins on experimental tooth movement in monkeys. J Dent Res.1982;61:1444-6.

5. Yamasaki K, Shibata Y, Imai S, Tani Y, Shibasaki Y, Fukuhara T. Clinical application of prostaglandin E1 [PGE1] upon orthodontic tooth movement. Am J Orthod 1984;85:508-18.

6. Lee W. Experimental study of the effect of prostaglandin administration on tooth movement with particular emphasis on the relationship to the method of PGE1 administration. Am J Orthod Dentofacial Orthop 1990;98:231-41.

7. Hou Y, Liang T, Luo C. Effects of IL-1 on experimental tooth movement in rabbits. Chin J Stoma 1997;32:46-8.

8. Mohammed AH, Tatakis DN, Dziak R. Leukotrienes in orthodontic tooth movement. Am J Orthod Dentofacial Orthop 1989;95:231-7.

9. Yamasaki K. The role of cyclic AMP, calcium, and prostaglandins in the induction of osteoclastic bone resorption associated with experimental tooth movement. J Dent Res 1983;62:877-81.

10. Takano-Yamamoto T, Kawakami M, Yamashiro T. Effect of age on the rate of tooth movement in combination with local use of $1,25[\mathrm{OH}] 2 \mathrm{D} 3$ and mechanical force in the rat. J Dent Res.1992;71:1487-92.

11. Collins MK, Sinclair PM. The local use of vitamin D to increase the rate of orthodontic tooth movement. Am J
Orthod Dentofacial Orthop 1988;94:278-84.

12. Davidovitch Z, Finkelson MD, Steigman S, Shanfeld JL, Montgomery PC, Korostoff E. Electric currents, bone remodeling, and orthodontic tooth movement. II. Increase in rate of tooth movement and periodontal cyclic nucleotide levels by combined force and electric current. Am J Orthod.1980;77:33-47.

13. Stark TM, Sinclair PM. Effect of pulsed electromagnetic fields on orthodontic tooth movement. Am J Orthod Dentofacial Orthop 1987;91:91-104.

14. Kawasaki K, Shimizu N. Effects of low-energy laser irradiation on bone remodeling during experimental tooth movement in rats. Laser Surg Med 2000;26:282-91

15. Hoogeveen EJ, Jansma J, Ren Y. Surgically facilitated orthodontic treatment: a systematic review. Am J Orthod Dentofacial Orthop. 2014;145:51-64.

16. Fleming PS, Fedorowicz Z, Johal A, El-Angbawi A, Pandis N. Surgical adjunctive procedures for accelerating orthodontic treatment. Cochrane Database Syst Rev. 2015; 6: CD010572.

17. Safaa S. Abed, Ali I. Al-Bustani. Corticotomy assisted orthodontic canine retraction. J Bagh Coll Dentistry 2013; 25: $160-166$

18. Suryavanshi HN, Das VR, Deshmukh A, Rai R, Vora M Comparison of rate of maxillary canine movement with or without modified corticotomy facilitated orthodontic treatment: A prospective clinical trial. APOS Trends Orthod 2015;5:138-43.

19. Alikhani M, Raptis M, Zoldan B, Sangsuwon C, Lee YB, Alyami B et al. Effect of micro-osteoperforations on the rate of tooth movement. Am J Orthod Dentofacial Orthop. 2013; 144 : 639-648.

20. PropelOrthodontics.Available a https://propelorthodontics. com. Accessed June 2018.

21. Teixeira CC, Khoo E, Tran J, Chartres I, Liu Y, Thant LM, Khabensky I, Gart LP, Cisneros G, Alikhani M. Cytokine expression and accelerated tooth movement. J Dent Res. 2010;89:1135-41.

22. Kapoor P, Kharbanda OP, Monga N, Miglani R, Kapila $S$. Effect of orthodontic forces on cytokine and receptor levels in gingival crevicular fluid: a systematic review. Prog Orthod. 2014;15:65.

23. Hao J. Accelerated orthodontic tooth movement with 
flapless corticotomy: a pilot study in beagle dogs. Master thesis, College of Dentistry, University of Illinois, Chicago, 2011.

24. Suya H. Corticotomy in orthodontics. In: Hösl E, Baldauf A, editors. Mechanical and Biological Basics in Orthodontic Therapy. Heidel-berg, Germany: Hüthig Buch Verlag; 1991.p. 207-26.

25. Wilcko MT, Wilcko WM, Breindel-Omniewski K, Bouquot JE, Wilcko JM. The periodontally 'accelerated osteogenic orthodontics' (PAOO) technique: Efficient space closing with either orthopedic or orthodontic forces. J Implant Adv Clin Dent 2009;1:45-68.

26. Mathews DP, Kokich VG. Accelerating tooth movement: The case against corticotomy-induced orthodontics. Am J Orthod Dentofacial Orthop 2013;144:5-13.

27. Echchadi Mel M. The role of alveolar corticotomies in orthodontic anchorage management. Int Orthod 2014; 12:171-87.

28. Chidchanok Leethanakul; Surat Kanokkulchai; Settakorn Pongpanich; Narit Leepong; Chairat Charoemratrote. Interseptal bone reduction on the rate of maxillary canine retraction. Angle Orthod. 2014;84:839-845.

29. Liou EJW, Huang CS. Rapid canine retraction through distraction of the periodontal ligament. Am J Orthod Dentofac Orthop. 1998; 114:372-382.

30. Singla L, Singla D. Rate of retraction of anterior teeth after canine distraction. Indian J Dent Sci 2017;9:261-5.

31. Ursi WJS, Almeida RR, Tavano O, Henriqes JFC. Assessment of mesiodistal axial inclination through panoramic radiography. J Clin Orthod. 1998; 24:166-173.

32. Germeç D, Giray B, Kocadereli I, Enacar A. Lower incisor retraction with a modified corticotomy. Angle Orthod 2006;76:882-90.

33. Kurol J, Owman-Moll P, Lundgren D. Time-related root resorption after application of a controlled continuous orthodontic force. Am J Orthod Dentofacial Orthop 1996;110:303-10.

34. Prabhat KC, Maheshwari S, Gupta ND, Verma SK, Goyal L. Periodontal ligament distraction: A simplified approach for rapid canine retraction. J Indian Soc Periodontol 2012;16:123-5.
35. Krishnan V, Davidovitch Z. On a path to unfolding the biological mechanisms of orthodontic tooth movement. J Dent Res 2009; 88:597-608.

36. Saritha Sivarajan; Jennifer Geraldine Doss; Spyridon N. Papageorgiou; Martyn T. Cobourne; Mang Chek Wey Mini-implant supported canine retraction with microosteoperforation: A split-mouth randomized clinical trial Angle Orthod. 2019;89:183-189.

37. Shashidhara Kamath Kateel, Amit Agarwal, Gagan Kharae, Vijay Prakash Nautiyal, Anant Jyoti, P. Narayana Prasad. A Comparative Study of Canine Retraction by Distraction of the Periodontal Ligament and Dentoalveolar Distraction Methods. J. Maxillofac. Oral Surg. 2016; 15:144-155.

38. Ren Y, Maltha JC. Van 't Hof MA, Kuijpers-Jagtman AM. Age effect on orthodontic tooth movement in rats. J Dent Res 2003;82: 38-42.

39. Ren Y, Kuijpers-Jagtman AM, Maltha JC. Immunohistochemical evaluation of osteoclast recruitment during experimental tooth movement in young and adult rats. Arch Oral Biol 2005;50:1032-9.

40. Okamoto A, Ohnishi T, Bandow K, Kakimoto K, Chiba N, Maeda A, et al. Reduction of orthodontic tooth movement by experimentally induced periodontal inflammation in mice. Eur J Oral Sci 2009; 117:238-47.

41. Bartzela T, Turp JC, Motschall E, Maltha JC. Medication effects on the rate of orthodontic tooth movement: a systematic literature review. Am J Orthod Dentofacial Orthop 2009;135:16-26.

42. Kumar KVS, Umashankar K, Kumar DP, Kumar DP. Evaluation of Canine Retraction through Distraction of the Periodontal Ligament: A Clinical Study. J Contemp Dent Pract 2012;13:799-805.

43. Sayin S, Bengi O, Gurton U, Ortakoglu K. Rapid canine distalization using distraction of the periodontal ligament: A preliminary clinical validation of the original technique. Angle Orthod 2004;74:304-15.

44. Kharkar VR, Kotrashetti SM, Kulkarni P. Comparative evaluation of dentoalveolar distraction and periodontal distraction assisted rapid retraction of maxillary canine: a pilot study. IJOMS. 2010; 39:1074-1079. 